06

\title{
Локальные механические свойства и кольцевая структура древесины, исследованные методом сканирующего наноиндентирования
}

\author{
() Ю.И. Головин, ${ }^{1,2}$ А.И. Тюрин, ${ }^{1}$ А.А. Гусев, ${ }^{1,3,4}$ С.М. Матвеев, ${ }^{1,3}$ Д.Ю. Головин, ${ }^{1}$ А.А. Самодуров, ${ }^{1}$ \\ И.А. Васюкова, ${ }^{1}$ М.А. Юнак, ${ }^{1}$ Е.А. Колесников, ${ }^{4}$ О.В. Захарова ${ }^{1,4}$ \\ ${ }^{1}$ Научно-исследовательский институт „Нанотехнологии и наноматериалы“, \\ Тамбовский государственный университет им. Г.Р. Державина, \\ 392000 Тамбов, Россия \\ ${ }^{2}$ Московский государственный университет им. М.В. Ломоносова, \\ 119991 Москва, Россия \\ ${ }^{3}$ Воронежский государственный лесотехнический университет им. Г.Ф. Морозова, \\ 394036 Воронеж, Россия \\ ${ }^{4}$ Национальный исследовательский технологический университет „МИСиС“, \\ 119049 Москва, Россия \\ e-mail: yugolovin@yandex.ru
}

Поступило в Редакцию 23 ноября 2021 г.

В окончательной редакции 27 декабря 2021 г.

Принято к публикации 8 января 2022 г.

Описаны результаты сканирования механических свойств древесины хвойных и лиственных пород (сосна обыкновенная, дуб черешчатый, липа мелколистная), проведенного на поперечных срезах методом наноиндентирования. Выявлено многократное увеличение микротвердости $H$ и модуля Юнга $E$ по мере перехода из зоны ранней древесины в зону поздней в каждом годовом кольце роста. Установлены значительные различия в ходе внутрикольцевых радиальных зависимостей $H$ и $E$ для каждой из исследованных пород. Установлено отсутствие зависимости $H$ и $E$ в ранней древесине от ширины годового кольца $w$, и обнаружена слабая их зависимость от $w$ в поздней древесине. Величина $w$, измеренная наноиндентированием, с точностью до $2-3 \%$ совпадает с измеренной традиционным оптическим методом. Разработанный метод и результаты могут быть полезны для углубления понимания природы и механизмов формирования макромеханических свойств древесины различных пород в зависимости от микроструктурных характеристик и условий роста, в задачах оптимизации технологий выращивания, упрочнения и условий последующего использования древесины, а также при разработке новых высокоинформативных методов дендрохронологии.

Ключевые слова: сканирование нано-/микротвердости и модуля Юнга, наноиндентирование, годовые кольца роста древесины, дендрохронология.

DOI: $10.21883 / J T F .2022 .04 .52245 .297-21$

\section{Введение}

С точки зрения физического материаловедения древесина - это природный, иерархически сложно структурированный композитный материал с ярко выраженной гетерогенностью, анизотропией всех свойств и способностью к регенерации (залечиванию дефектов). В структуре древесины можно выделить (весьма условно) несколько масштабно-иерархических уровней (рис. 1) - атомно-молекулярный, нано- (нанокристаллы, нанофибриллы), микро- (микроволокна, клеточные стенки), мезо- (клетки, крупные сосуды) и макро- (годовые кольца, макродефекты строения, трещины и т.п.). Каждый из них вносит свой вклад в формирование всего комплекса физико-химических свойств.

В последние полтора-два десятилетия к исследованиям микроструктуры и свойств древесины стали привлекать современные методы и средства, традиционные в физике твердого тела и физическом материаловедении [1]. Микроструктуру изучают с помощью электронной просвечивающей и сканирующей микроско- пии, сканирующей зондовой (преимущественно атомносиловой), конфокальной лазерной и оптической микроскопии в различных модах [2-4]. Характер и степень упорядоченности молекул целлюлозы в нановолокнах определяют методом рентгеновской дифрактометрии [5,6], синхротронного рентгеновского излучения [7] и малоуглового рентгеновского рассеяния. Элементный и молекулярный составы выявляют различными спектроскопическими методами. Используют инфракрасную (ИК) и ИК с Фурье преобразованием (FTIR) [8-10], рамановскую [10-12], бриллюэновскую [13] и ядерномагнито-резонансную [14] спектроскопию, рентгенофлуоресцентный анализ [15] и другие аналитические методы. Сравнительный анализ возможностей наиболее распространенных физических методов исследования молекулярной, субклеточной и клеточной структуры древесины можно найти в недавних обзорах [16,17].

Механические свойства древесины в нано- и микрошкале исследуют, как и в других материалах, методами нано-/микро-механического тестинга [18-21], чаще 


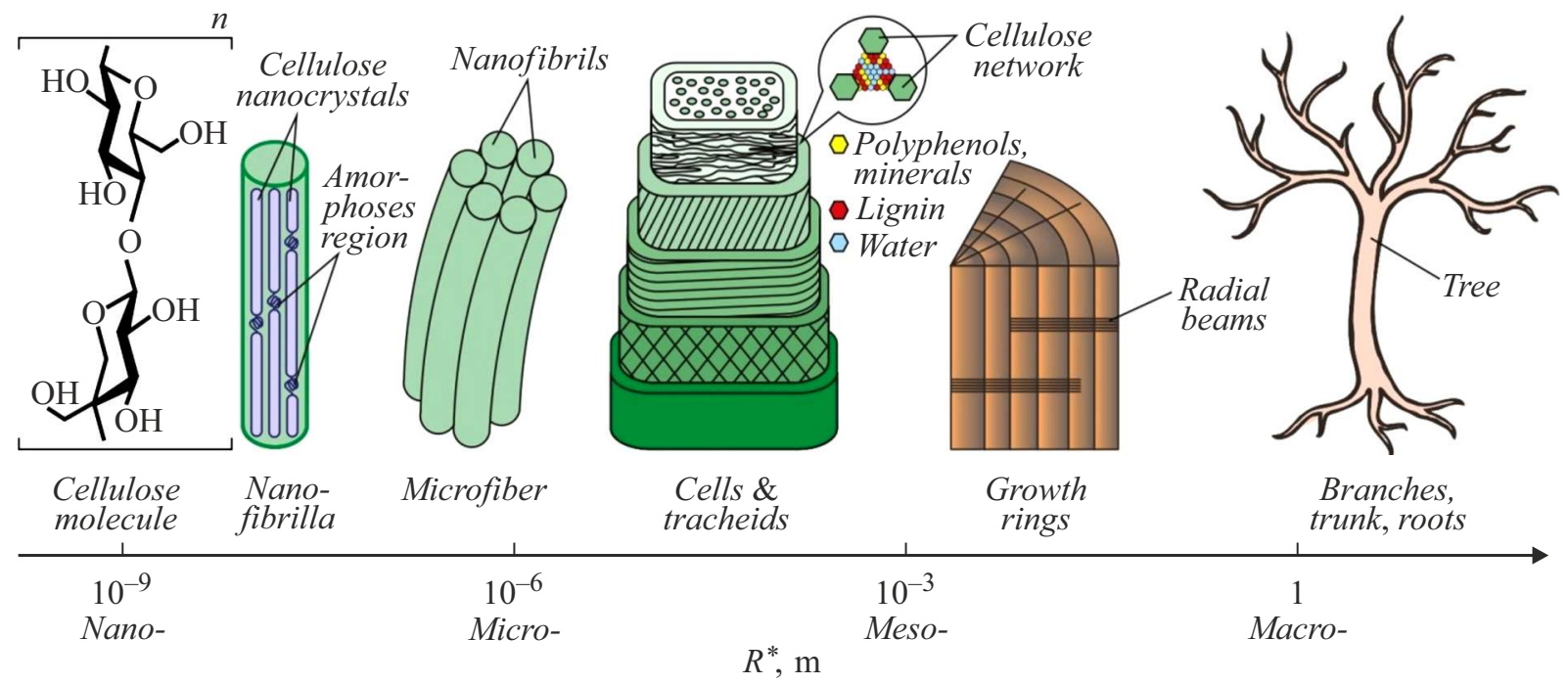

Рис. 1. Масштабно-иерархические уровни структуры древесины.

всего с помощью атомно-силовых микроскопов [22-25] и наноиндентометров [26-34]. Так, методами нано/микромеханики изучали механические свойства отдельных нанофибрилл и микроволокон целлюлозы [2,35-37], клеточных стенок [16,38-41] древесины различных пород и получили много интересных данных, однако они относились к определенным локациям и элементам нано- и микроструктуры и не предполагали картирования механических свойств областей, охватывающих несколько годовых колец роста. Это не позволяет проследить связь свойств отдельных нано- и микроструктурных элементов древесины с ее макромеханическими свойствами, шириной годовых колец роста, долей поздней древесины в них и т.д.

В противоположность современным микроструктурным и физико-химическим исследованиям древесины, основным инструментом картирования мезоструктуры, изучения и анализа годовых колец являются простые оптические методы, в которых первичная информация основана на различии отражательных способностей ранней и поздней древесины. Их применяют как для выяснения природы и прогнозирования прочности и других служебных свойств, так и в интересах дендрохронологии и дендроклиматологии. Следует подчеркнуть, что с помощью этих методов извлекают чисто геометрические и морфологические характеристики объекта изучения, такие, как ширина годовых колец роста, доля ранней и поздней древесины в них, вариации этих параметров от кольца к кольцу и т.д. Предпринимались многочисленные попытки усовершенствования оптических методов дендрохронологии, главным образом, путем модификации методов пробоподготовки, использования не белого, а синего света, применения технологий технического зрения и математической обработки данных (см., например, [4,42-45]). Однако, несмотря на это, возможности подхода, в основе которого лежит фоторегистрация и анализ изображения поперечного среза, остаются сильно ограниченными, поскольку отражательные оптические свойства древесины весьма изменчивы и неоднозначно или очень слабо связаны с другими ее физическими характеристиками, в частности, с механическими.

Известны попытки применения современных физических методов для пространственного картирования свойств дерева, в частности, методами рассеяния синхротронного излучения [7], $3 D$ рентгеновской компьютерной [46-49] и магниторезонансной томографии [50]. Однако эти методы сложны в реализации, трудоемки и требуют дорогостоящего или уникального оборудования, поэтому они применяются редко. Более простым является метод рентгеновской денситометрии, но он требует двустороннего доступа к плоскому образцу, вырезанному строго перпендикулярно длинным осям клеток и сосудов [51].

В настоящей работе описан простой способ сканирования поперечного среза древесины с помощью современной наноиндентометрии (НИ), дающий возможность по заданной программе измерять в автоматическом режиме нано-/микротвердость $H$, модуль Юнга $E$ и другие локальные механические характеристики [27-34] во многих сотнях заранее запрограммированных точек на поверхности образца, т. е. картировать механические свойства. Этот подход имеет несколько преимуществ перед традиционным, основанным на анализе изображения поперечного среза: он позволяет исключить человеческий фактор и регистрировать объективную информацию о локальных физико-механических свойствах с высоким пространственным разрешением (до единиц-десятков нанометров при необходимости), а затем использовать ее в различных целях. В частности, полученные данные могут быть полезны, во-первых, для углубления понимания природы и механизмов формирования макромеханических свойств древесины и волокнистых (в частности, 
целлюлозо-содержащих) композитов в зависимости от микроструктурных характеристик, во-вторых, в задачах оптимизации технологий выращивания, упрочнения и условий последующего использования древесины и композитов, содержащих природные волокна, и, в третьих, при разработке новых, независимых количественных методов дендрохронологии и дендроклиматологии, дополняющих или заменяющих традиционные.

Конкретные цели настоящей работы состояли в выявлении распределения эффективных значений модуля Юнга $E$ и твердости $H$ внутри годовых колец и слоев ранней и поздней древесины, а также их границ и ширины методом НИ.

\section{1. Материалы и методы}

Материалы для исследований отбирали в июне-сентябре 2021 г. при проведении выборочных санитарных рубок в естественных древостоях лесов Центральночерноземного региона РФ. Спилы сосны обыкновенной (Pinus sylvestris L.) 110-125 летнего возраста происходили из Вернадского лесничества Тамбовской области (Цнинский лесной массив), а спилы дуба черешчатого (Quercus robur) возрастом 90-110 лет и липы мелколистной (Tília cordáta) возрастом 70-90 лет из Учебно-опытного лесхоза Воронежского государственного лесотехнического университета им. Г.Ф. Морозова (Правобережное участковое лесничество).

Образцы размерами $30 \times 30 \times 100 \mathrm{~mm}$ для исследования выпиливали из поперечных срезов древесины и высушивали до уровня $10-12 \%$ влажности в сушильной камере по мягкому режиму сушки при температуре $75^{\circ} \mathrm{C}$, что занимало от 24 до $72 \mathrm{~h}$. Подготовку поверхности проводили методами механической шлифовки и полировки при помощи шлифовальнополировального комплекса (Buhler, USA) абразивами с уменьшающимся после каждой стадии обработки зерном. Шероховатость $R_{a}$ обработанной поверхности определяли с помощью сканирующего зондового микроскопа di Innova SPM (Veeco-Digital Instruments, USA). Типичная величина $R_{a}$ для образцов сосны и липы составляла $250-300 \mathrm{~nm}$, а для дуба - 140-180 nm. Микроструктуру образцов контролировали с помощью сканирующего электронного микроскопа (СЭМ) модели Tescan Vega 3. Поверхность для электронно-микроскопического исследования образовывали путем удаления тонкого слоя древесины с поперечного среза отшлифованных образцов при помощи микротома. Типичные изображения годовых колец роста и клеточной структуры в исследуемых образцах представлены на рис. 2.

Картирование механических свойств отобранных образцов древесины осуществляли на наноиндентометре (НИ) Triboindenter TI-950 (Hysitron, USA). Фактически он является прецизионной нано-/микромеханической испытательной машиной, регистрировавшей диаграмму $P-h$ (нагрузка-деформация) с пас- портным разрешением $\sim 50 \mathrm{nN}$ по силе $P$ и $\sim 0.5 \mathrm{~nm}$ по перемещению $h$ при вдавливании в поверхность образца острого (радиус закругления в вершине 20-50 nm) треугольного алмазного индентора Берковича. Штатное программное обеспечение позволяет запрограммировать рабочий цикл нагружения-разгрузки (профиль силы во времени), а прецизионный компьютеризированный трехкоординатный столик - осуществить картирование механических свойств по многим точкам (до $\sim 10^{3}$ ) с заранее заданными координатам на поверхности образца без дальнейшего участия оператора. Измерения проводили в соответствии с ISO 14577 [52] и ГОСТ 8.7482011 [53], разработанными для НИ. Для целей настоящего исследования максимальная нагрузка $P_{\max }$, приложенная к индентору, была выбрана равной $500 \mathrm{mN}$, что обеспечивало образование отпечатков глубиной на 1.5-2 порядка величины превышающей параметр шероховатости $R_{a}$. Эти первичные данные обрабатывали по методу Оливера-Фарра [54-56], включенному в международные и Российские стандарты $[52,53]$, и извлекали из них величины $H$ и $E$.

Важно отметить, что при выбранной нами максимальной нагрузке $P_{\max }=500 \mathrm{mN}$ латеральный размер зоны деформации $(80-130 \mu \mathrm{m})$ в $3-5$ раз превышал поперечный размер клеток, что приводило к усреднению механических характеристик по 10-25 рядом расположенным клеткам с учетом и клеточных стенок, и капилляров. Измеренные таким образом значения $E$ и $H$ можно рассматривать как эффективные для данного слоя древесины. Каждая точка на графиках получена усреднением результатов от 5 до 10 индивидуальных измерений, сделанных на независимых отпечатках в одинаковых условиях и на одном и том же расстоянии от начала нового годового кольца.

Как известно, в структуре каждого годичного кольца роста в древесине любой породы имеется „ранняя“ и „поздняя“ древесина (EW - Early Wood и LW - Late Wood соответственно). Первая формируется в весенние месяцы и характеризуется низкой плотностью и прочностью, а вторая - в летне-осенний период и отличается несколько большей плотностью и гораздо более высокими механическими свойствами. Сознательно выбранная нами нагрузка на индентор $500 \mathrm{mN}$ (и соответственно латеральные размеры области локальной деформации) позволяли снизить дисперсию значений $H$ и $E$ по сравнению с данными [57,58], полученными при гораздо меньшей нагрузке $P_{\max }$ на индентор $(2 \mathrm{mN})$, и вместе с тем уверенно строить распределения $E$ и $H$ внутри отдельных колец роста при не слишком большом числе требуемых отпечатков. Анализируя эти распределения, можно не только определять точное положение границ годовых колец и их ширину, но и дифференцировать внутрикольцевые слои древесины. Это дает возможность связать механические свойства в каждом из годовых колец с условиями роста не только по годам, но и внутри сезона роста, что недоступно традиционным 

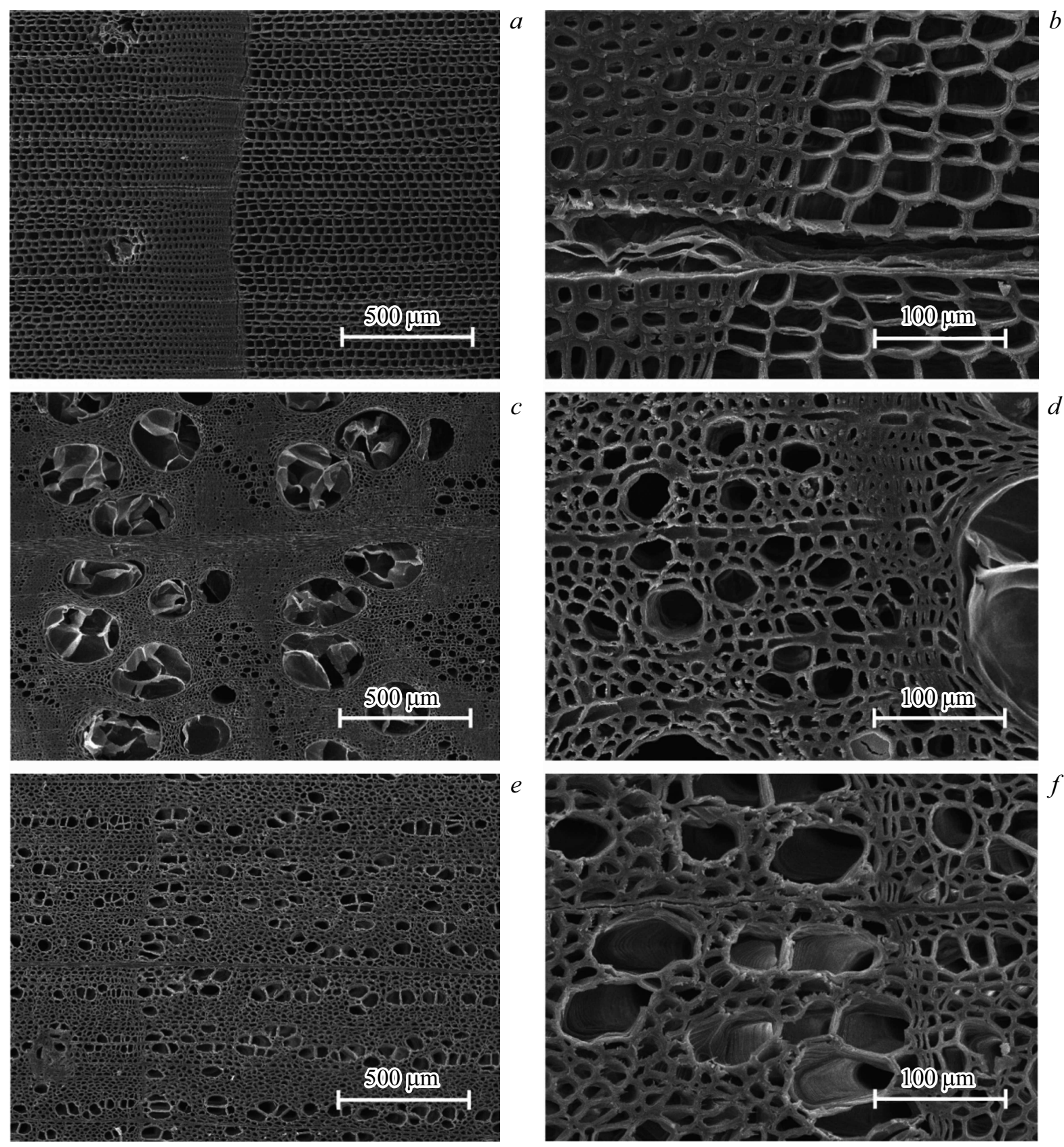

Рис. 2. СЭМ изображения поперечного среза образца сосны обыкновенной $(a, b)$, дуба черешчатого $(c, d)$ и липы мелколистной $(e, f)$ при двух увеличениях. Границы между годовыми кольцами, характеризующиеся скачкообразным изменением морфологии и размеров клеток и трахеид, расположены вертикально.

методам исследования, основанным на анализе изображения. Данная методика может найти применение в дендрохронологии и дендроклиматологии, дополнив или заменив традиционные методы, основанные на вариациях оптических свойств, объективными количественными мерами, несущими, кроме информации о чисто геометрических характеристиках структуры древесины, еще и информацию о ее механических свойствах.

Макроскопические механические свойства определяли методом индентирования по Бринеллю вдавливанием керамического шарика диаметром $12.7 \mathrm{~mm}$ в торцевую поверхность поперечного спила ствола древесины на глубину до $1 \mathrm{~mm}$. Зона деформирования при этом включала несколько годовых колец. Это позволяло сравнить макроскопические и микроскопические значения твердости, полученные на одном образце, и сопоставить их с литературными данными.

\section{2. Экспериментальные результаты}

Типичные первичные данные в виде $P-h$-диаграмм, полученных при индентировании трех видов исследо- 

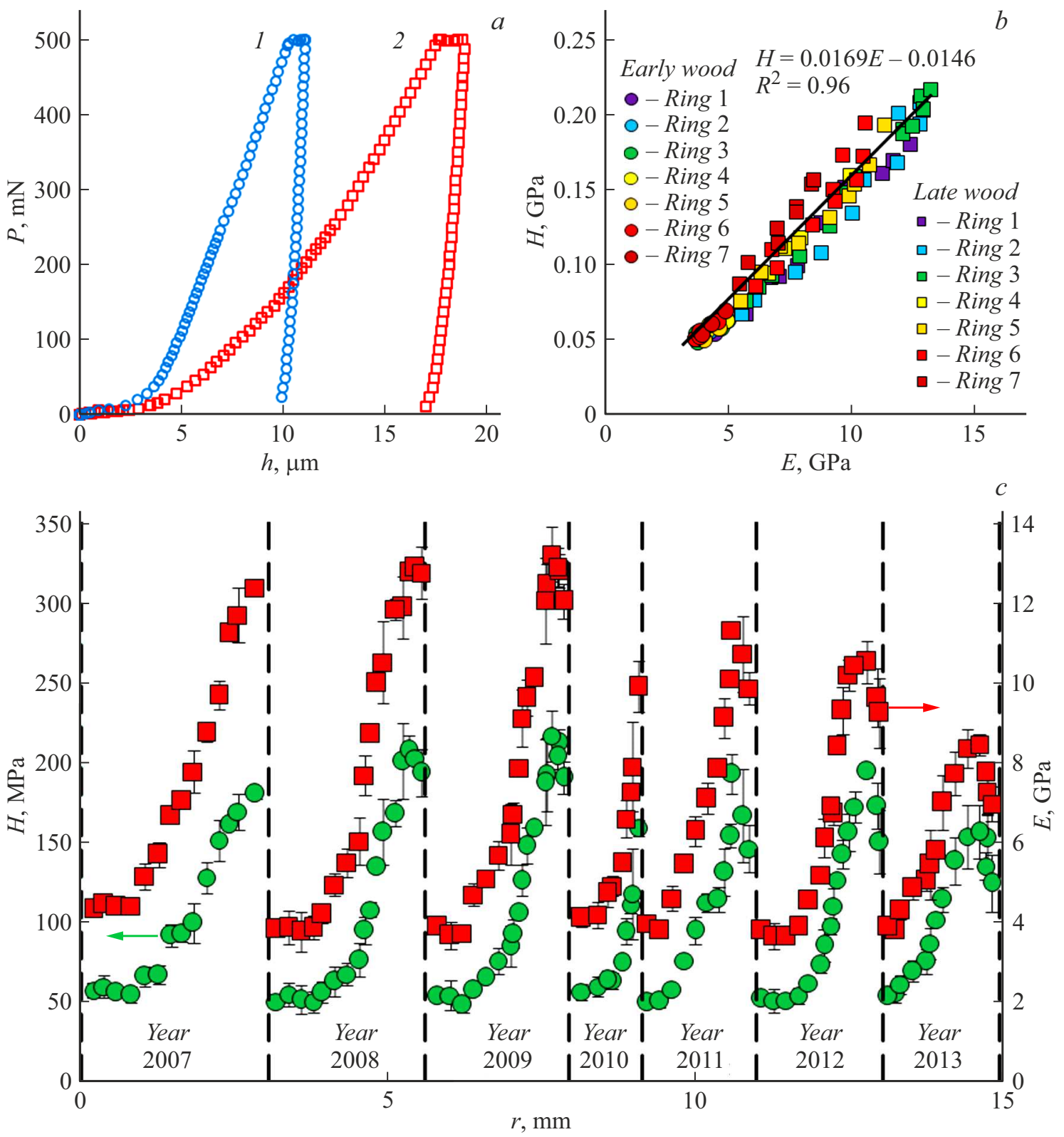

Рис. 3. Микромеханические свойства годовых колец древесины сосны обыкновенной, исследованные методом сканирующего наноиндентирования при максимальной нагрузке, приложенной к индентору Берковича, $P_{\max }=500 \mathrm{mN} ; a-$ характерные $P-h$ диаграммы для поздней $(1)$ и ранней $(2)$ древесины; $b$ - зависимости твердости $H$ от модуля Юнга $E$ для семи последовательных годовых колец; $c$ - зависимости $H$ и $E$ от расстояния поперек годовых колец $r$ (для семи последовательных годовых колец). Границы годовых колец показаны штриховыми линиями.

ванной древесины, показаны на рис. 3, $a, 4, a, 5, a$. Эти диаграммы являются аналогом диаграмм $\sigma-\varepsilon$, широко используемых в исследованиях и описаниях макроскопических механических свойств материалов (здесь $\sigma$ - напряжение, $\varepsilon-$ относительная деформация), но регистрируемые с нанометровым разрешением. $P-h$-диаграммы содержат информацию об упругих, пластических и вязкоупругих свойствах исследуемого материала, модуле Юнга, твердости, скорости ползучести, коэффициентах деформационного упрочнения и других физико-механических характеристиках материала, кото- рые могут быть извлечены с помощью различных методов, в частности, наиболее часто используемого метода Оливера-Фарра [54-56]. Нанометровое разрешение по $h$ позволяет регистрировать и анализировать элементарные деформационные события в локализованной под индентором области, непрерывно увеличивающейся по мере погружения пирамидального индентора от единиц $\mathrm{nm}$ до сотен $\mu \mathrm{m}$. Основные результаты по определению радиальной зависимости $H$ и $E$ на поперечных срезах древесины представлены на рис. $3, b, 4, b, 5, b$. Из этих рисунков следует, что во всех трех видах 

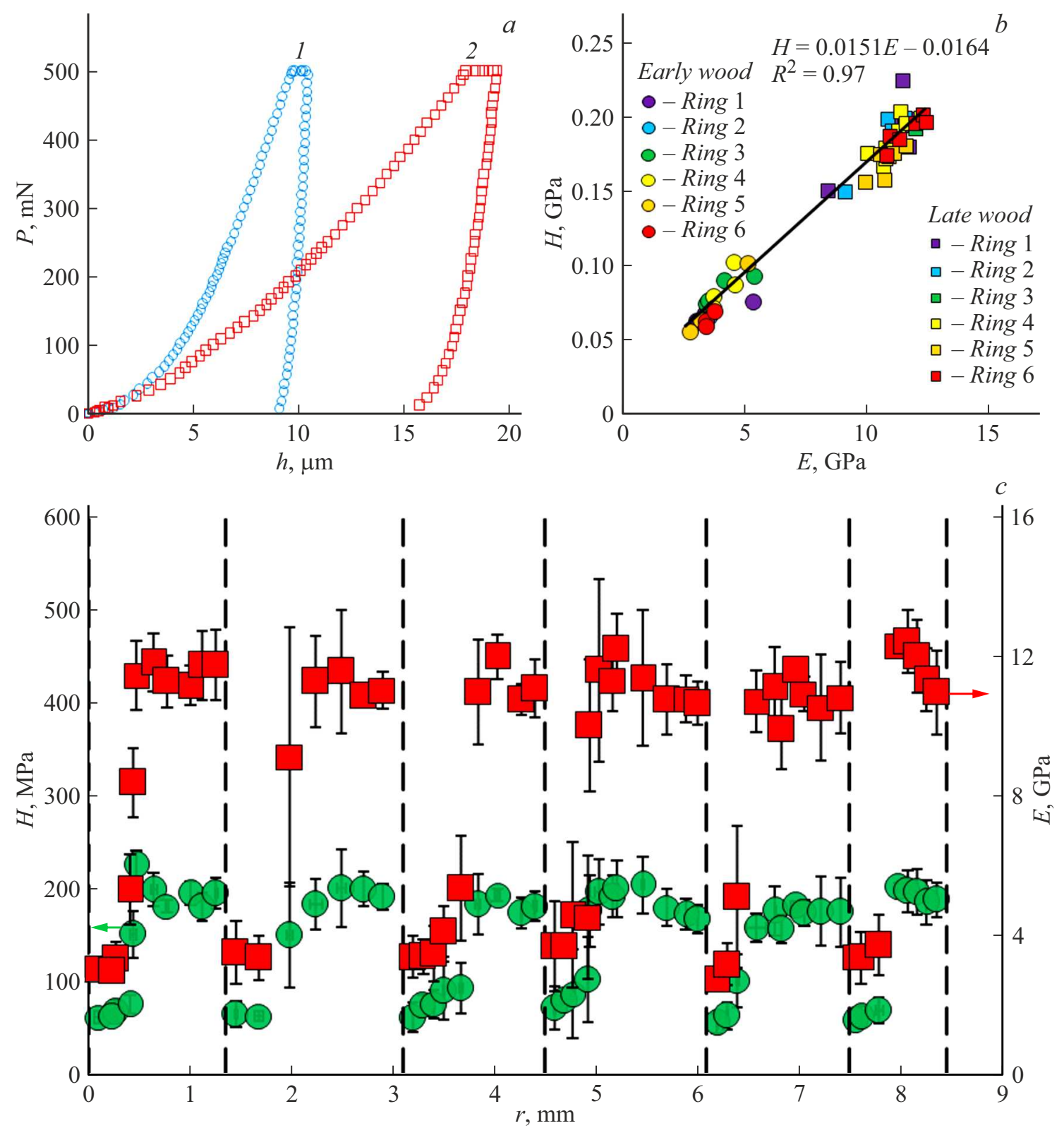

Рис. 4. Микромеханические свойства годовых колец древесины дуба черешчатого, исследованные методом сканирующего наноиндентирования при максимальной нагрузке, приложенной к индентору Берковича, $P_{\max }=500 \mathrm{mN} ; a-$ характерные $P-h$ диаграммы для поздней $(1)$ и ранней $(2)$ древесины; $b$ - зависимости твердости $H$ от модуля Юнга $E$ для шести последовательных годовых колец; $c$ - зависимости $H$ и $E$ от расстояния поперек годовых колец $r$ (для шести последовательных годовых колец). Границы годовых колец показаны штриховыми линиями.

древесины наблюдается ярко выраженная периодичность локальных механических свойств. Скачкообразное изменение $E$ и $H$ согласуется с положением границ годовых колец, выявляемых оптически по изменению цвета древесины. Внутри годовых колец сосны и липы $E$ и $H$ меняются плавно при переходе от EW к LW, а в дубе - скачкообразно. Между $H$ и $E$ наблюдалась линейная связь с практически одинаковым коэффициентом наклона $m=0.017 \pm 0.002$ (рис. 3,c, 4, c, 5,c). Другими словами, индекс вязкости (The Ductility Ratio) $\mathrm{DR}=E / H$ составлял во всех трех видах древесины около 60, что типично для многих пород (например, в эвкалипте DR лежит в интервале от 54 до 68 [59] и в среднем составляет 61, а в буке $\mathrm{DR} \approx 55$ [60]).

Значения $H$ и $E$ внутри каждого слоя $\mathrm{EW}$ варьируются в разных годовых кольцах и внутри этих колец не очень сильно ( 10\%), несмотря на то, что погодные условия роста в разные годы были существенно различными. Так, например, 2010 год был очень засушливым, что отразилось на ширине годового кольца $w$ (в частности, в сосне величина $w$ уменьшилась более чем вдвое по сравнению с предыдущими годами), но это практически 

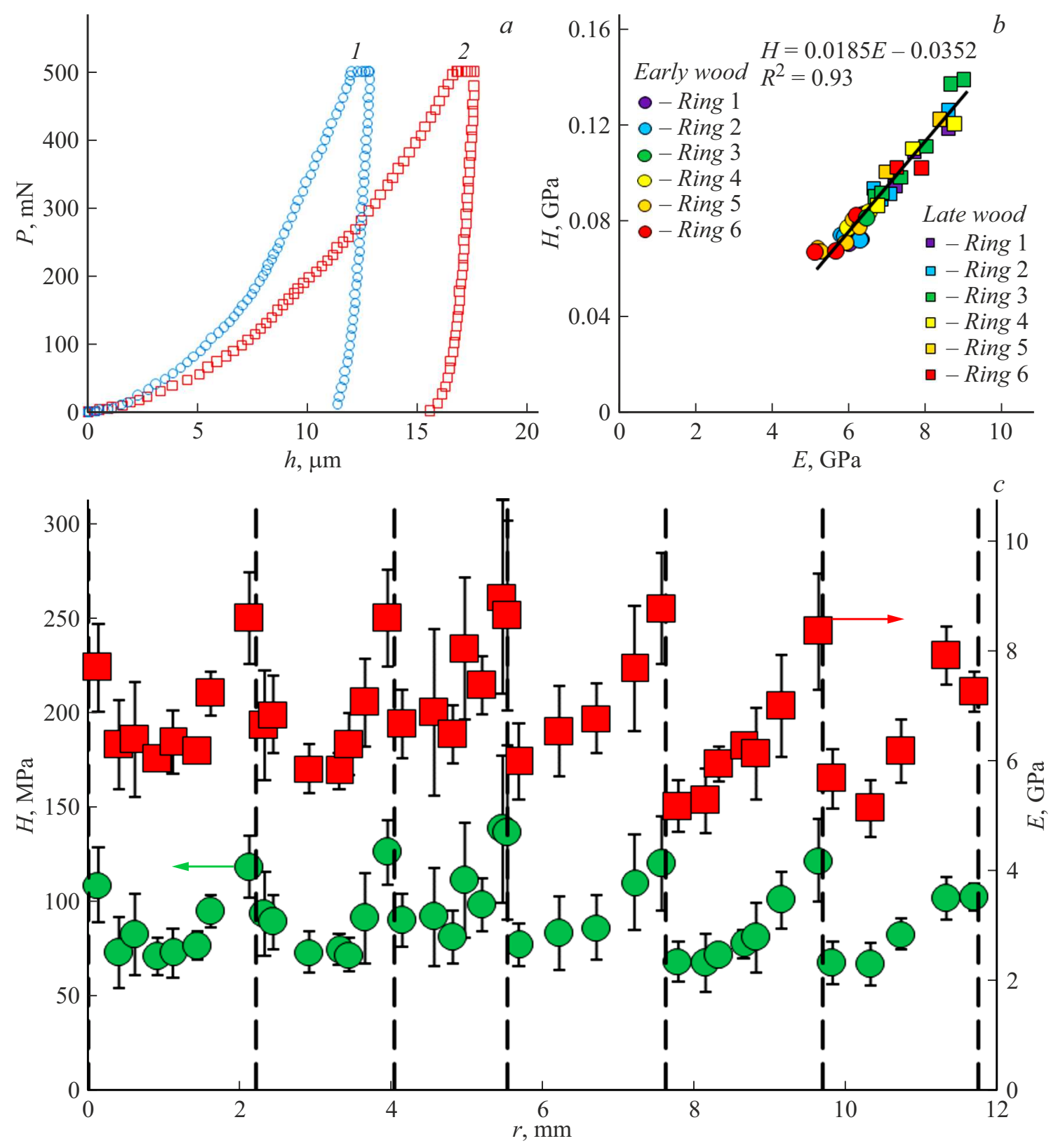

Рис. 5. Микромеханические свойства годовых колец древесины липы мелколистной, исследованные методом сканирующего наноиндентирования при максимальной нагрузке, приложенной к индентору Берковича, $P_{\max }=500 \mathrm{mN} ; a-$ характерные $P-h$ диаграммы для поздней $(1)$ и ранней $(2)$ древесины; $b$ - зависимости твердости $H$ от модуля Юнга $E$ для шести последовательных годовых колец; $c$ - зависимости $H$ и $E$ от расстояния поперек годовых колец $r$ (для шести последовательных годовых колец). Границы годовых колец показаны штриховыми линиями.

не повлияло на величину $H$ и $E$ (рис. $3, b)$ в $\mathrm{EW}$. Поперечный размер клеток в разных годовых кольцах также не отличался в EW радикально, но заметно отличался толщиной клеточных стенок (рис. 2). Таким образом, вариации ширины годовых колец происходят, главным образом, за счет разного количества клеток в слое, мало отличающихся по размерам и механическим свойствам.

Различия механических свойств в EW и LW в нескольких типичных кольцах роста показаны в обобщающей таблице. Из нее видно, что усредненная величина $E$ в LW у сосны больше, чем в $\mathrm{EW}$, в 3.1 раза, у дуба - в 3.5 раза, а у липы - в 1.3 раза. Различия в твердости LW и EW того же порядка величины в сосне в 3.7 раза, дубе - в 3.0 раза, а в липе в 1.6 раза. Эти соотношения в среднем характерны и для соседних колец роста, однако в отдельные годы они могут существенно отличаться от средних. Например, в 5-м и 6-м кольце в дубе твердость EW примерно в 3 раза выше, чем в предыдущих кольцах при примерно 
Механические характеристики элементов структуры древесины сосны, дуба и липы на разных масштабных уровнях

\begin{tabular}{|c|c|c|c|c|c|c|c|c|c|c|}
\hline \multirow{4}{*}{$\begin{array}{c}\text { Номер } \\
\text { иссле- } \\
\text { дуемого } \\
\text { годового } \\
\text { кольца }\end{array}$} & \multirow{2}{*}{\multicolumn{5}{|c|}{$\begin{array}{l}\text { Микромеханические свойства (результаты, } \\
\text { полученные методом наноиндентирования) }\end{array}$}} & \multicolumn{5}{|c|}{ Макромеханические свойства } \\
\hline & & & & & & \multirow{3}{*}{\begin{tabular}{|c|}
$\begin{array}{c}\text { Измеренные } \\
\text { в работе }\end{array}$ \\
$H_{\mathrm{B}}$ \\
$\mathrm{MPa}$
\end{tabular}} & \multicolumn{4}{|c|}{ Табличные } \\
\hline & \multirow{2}{*}{$\begin{array}{c}\text { Доля } \\
\text { поздней } \\
\text { древесины } \\
m, \%\end{array}$} & \multicolumn{2}{|c|}{ Ранняя древесина } & \multicolumn{2}{|c|}{ Поздняя древесина } & & \multicolumn{2}{|c|}{$\begin{array}{c}\text { Среднее, без разделения } \\
\text { на раннюю и позднюю } \\
\text { древесину }\end{array}$} & \multirow{2}{*}{\begin{tabular}{|c|}
$\begin{array}{c}\text { Ранняя } \\
\text { древесина }\end{array}$ \\
$H_{e t}$, \\
$\mathrm{MPa}$
\end{tabular}} & \multirow{2}{*}{$\begin{array}{c}\text { Поздняя } \\
\text { древесина } \\
H_{l t}, \\
\mathrm{MPa}\end{array}$} \\
\hline & & $\begin{array}{c}E_{e}, \\
\mathrm{GPa}\end{array}$ & $\begin{array}{l}H_{e} \\
\mathrm{MPa}\end{array}$ & $\begin{array}{c}E_{l}, \\
\mathrm{GPa}\end{array}$ & $\begin{array}{l}H_{l} \\
\mathrm{MPa}\end{array}$ & & $\begin{array}{c}E_{t} \\
\mathrm{GPa}\end{array}$ & $\begin{array}{l}H_{t} \\
\mathrm{MPa}\end{array}$ & & \\
\hline \multicolumn{11}{|c|}{ Сосна обыкновенная (Pinus sylvestris) } \\
\hline 1 & 26.6 & $4.39 \pm 0.04$ & $56.7 \pm 1.6$ & $12.35 \pm 0.68$ & $180.1 \pm 10.9$ & \multirow[t]{3}{*}{$44.1 \pm 4.6$} & \multirow[t]{3}{*}{$\begin{array}{l}12.1[66] \\
11.3[68]\end{array}$} & \multirow[t]{3}{*}{$\begin{array}{c}27-31[67] \\
27[69]\end{array}$} & \multirow[t]{3}{*}{$\begin{array}{l}20.6 \\
{[68]}\end{array}$} & \multirow[t]{3}{*}{$\begin{array}{c}105.4 \\
{[68]}\end{array}$} \\
\hline 2 & 38.8 & $3.89 \pm 0.12$ & $52.3 \pm 2.3$ & $12.78 \pm 0.28$ & $201.2 \pm 9.1$ & & & & & \\
\hline 3 & 34.8 & $3.75 \pm 0.25$ & $51.9 \pm 5.7$ & $12.78 \pm 0.69$ & $212.2 \pm 4.3$ & & & & & \\
\hline \multicolumn{11}{|c|}{ Дуб черешчатый (Quercus robur) } \\
\hline 1 & 65.2 & $3.09 \pm 0.16$ & $63.7 \pm 2.6$ & $11.07 \pm 0.77$ & $189.3 \pm 16.2$ & \multirow[t]{3}{*}{$66.6 \pm 3.6$} & \multirow[t]{3}{*}{$14.3[66]$} & \multirow[t]{3}{*}{$25-42[67]$} & \multirow[t]{3}{*}{$52.4[68]$} & \multirow[t]{3}{*}{$92.7[68]$} \\
\hline 2 & 63.2 & $3.42 \pm 0.07$ & $63.9 \pm 1.3$ & $11.14 \pm 0.27$ & $196.6 \pm 3.9$ & & & & & \\
\hline 5 & 65.5 & $2.93 \pm 0.22$ & $58.8 \pm 3.9$ & $10.81 \pm 0.39$ & $172.8 \pm 5.5$ & & & & & \\
\hline \multicolumn{11}{|c|}{ Липа мелколистная (Tília cordáta) } \\
\hline 1 & 34.9 & $6.68 \pm 0.14$ & $75.4 \pm 3.5$ & $8.59 \pm 0.84$ & $118.4 \pm 16.4$ & \multirow[t]{3}{*}{$46.5 \pm 2.5$} & \multirow[t]{3}{*}{-} & \multirow[t]{3}{*}{$19[69]$} & \multirow[t]{3}{*}{-} & \multirow[t]{3}{*}{-} \\
\hline 2 & 32.9 & $5.99 \pm 0.21$ & $73.5 \pm 0.9$ & $8.59 \pm 0.88$ & $126.3 \pm 16.9$ & & & & & \\
\hline 3 & 48.6 & $6.68 \pm 0.14$ & $87.9 \pm 4.3$ & $8.81 \pm 0.17$ & $137.6 \pm 0.9$ & & & & & \\
\hline
\end{tabular}

одинаковой твердости LW. Очевидно, такое различие обусловлено особенностями климатических условий в эти аномальные периоды, что заметно и по меньшей ширине колец в эти годы. Однако разница в твердости в разные годы намного больше, чем в ширине колец, по которым обычно судят об изменении климатических условий в ретроспективе. Это означает, что измерение твердости с высоким пространственным разрешением может быть гораздо более чувствительным и точным методом дедроклиматологии, чем по измерению вариаций в ширине колец роста.

Механические свойства LW в сосне проявляют слабую чувствительность к условиям роста и ширине годовых колец (рис. 6), в то время как в дубе (рис. 7) и липе она практически отсутствовала, как и в EW во всех исследованных годовых кольцах.

Обсудим другую важную механическую характеристику древесины - нанотвердость клеточных стенок $H_{c}$. В разных слоях и годовых кольцах и даже в различных породах дерева она отличается не сильно. Приведем несколько результатов работ, в которых методом НИ определяли нанотвердость $H_{c}$ клеточных стенок в продольном направлении. Так, в [40] в клеточных стенках сосны обыкновенной (Pinus sylvestris L.) $H_{c}$ в молодой древесине (7-е годовое кольцо) составляла в $\mathrm{EW}$ $439 \mathrm{MPa}$, а в LW - $466 \mathrm{MPa}$; в зрелой древесине (74-е годовое кольцо) в $\mathrm{EW}-469 \mathrm{MPa}$, а в LW $489 \mathrm{MPa}$. В [61] в сосне (Pinus massoniana Lamb.) твердость клеточной стенки варьировалась в интервале 0.35-0.42 GPa независимо от того, была ли ее внутренняя полость заполнена пластиком при ламинировании или нет. Авторами [62] найдено, что твердость клеточной стенки в древесине сосны Masson pine составляла 0.41-0.53 GPa и в пределах рассеяния результатов не отличалась для EW и LW, а авторами [63] в сосне ладанной (Pinus taeda) $H_{c}=0.34-0.54 \mathrm{GPa}$ (без дифференцирования на раннюю и позднюю древесину).

Приведенные данные о величине $H_{c}$ свидетельствуют о близости структуры клеточных стенок различных слоев и пород древесины. Относительные различия между ними имеют значительно меньшую величину, чем у измеренных нами эффективных микроскопических характеристик $E$ и $H$, макротвердости по Бринеллю $H_{\mathrm{B}}$ и табличных макроскопических свойств. Однако по абсолютной величине $H_{c}$ всегда превышает микротвердость $H$, измеренную в настоящей работе, и, тем более, макротвердость и макропрочность. Формально это можно расценивать как проявление размерного эффекта (РЭ) в механических свойствах древесины. Однако вопрос, какую часть этого РЭ можно отнести на счет сплошного материала древесины, а какую на счет пор, требует отдельного исследования. 

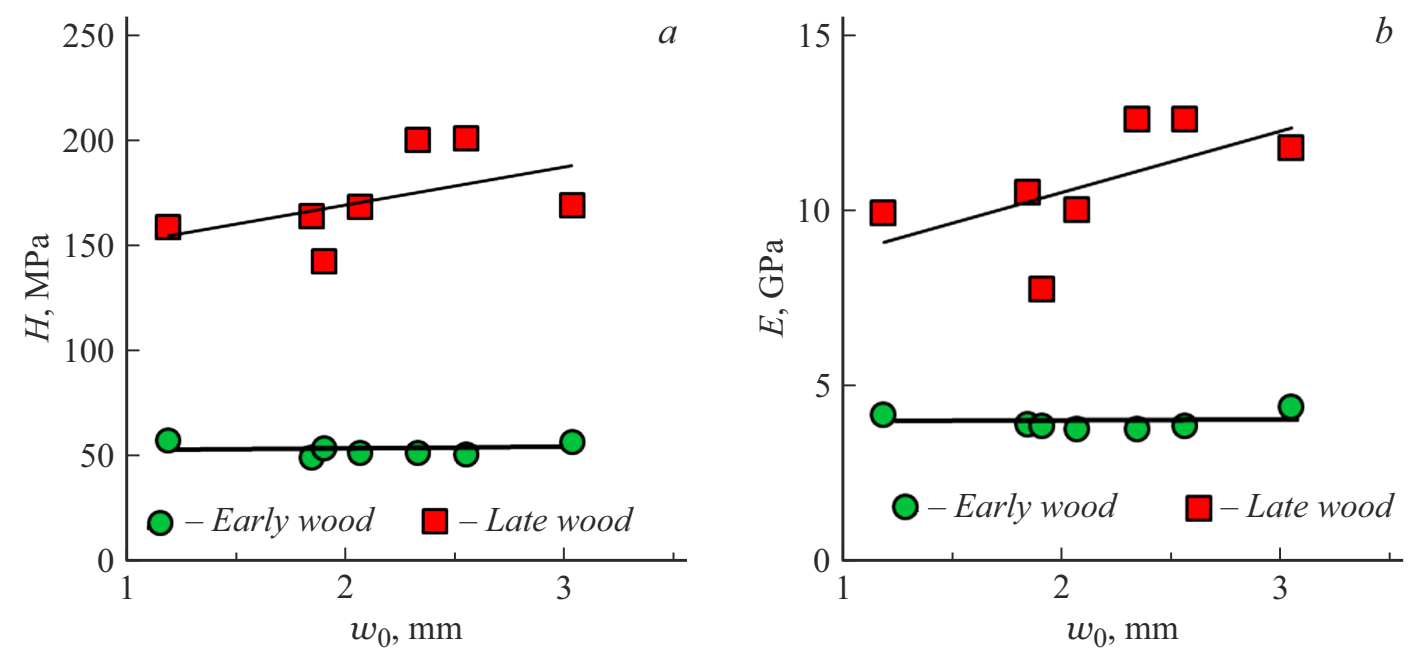

Рис. 6. Зависимость твердости $H(a)$ и модуля Юнга $E(b)$ для ранней и поздней древесины сосны обыкновенной от ширины $w_{0}$ годового кольца, измеренной оптическим методом.
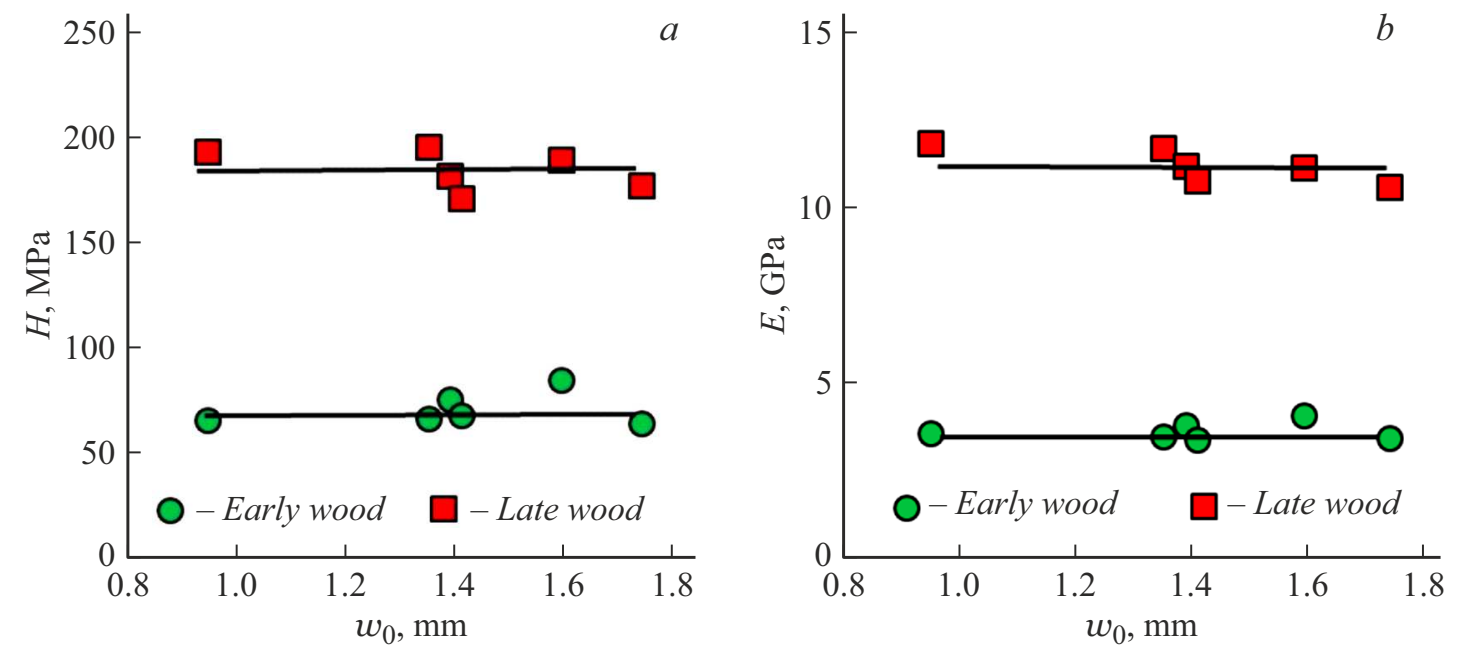

Рис. 7. Зависимость твердости $H(a)$ и модуля Юнга $E(b)$ для ранней и поздней древесины дуба черешчатого от ширины $w_{0}$ годового кольца, измеренной оптическим методом.

\section{3. Обсуждение}

В отношении природы физико-механических свойств и размерных эффектов в древесине на разных масштабноиерархических уровнях имеется не так много связанной информации. Приведем наиболее интересные типичные данные. Расчетная прочность и элементарных целлюлозных нанокристаллов, и нанофибрилл диаметром $3-15 \mathrm{~nm}$ составляет 4.9-10 GPa [1]. С этим согласуются также данные обработки рамановских спектров и испытаний на трехточечный изгиб с помощью атомносиловых микроскопов [2]. Прочность микроволокон диаметром $8-12 \mu \mathrm{m} \quad(0.8-1.57 \mathrm{GPa})[36,37,64]$ примерно на порядок величины ниже. Нанотвердость клеточных стенок с типичной толщиной $2-5 \mu \mathrm{m}$ лежит в интервале $0.3-0.6 \mathrm{GPa}[38-41,59,65]$, т.е. в $3-5$ раз меньше, чем прочность микроволокон целлюлозы. Как следует из таблицы, локальные величины $H$, измеренные нами методом НИ, во всех трех породах древесины как в слоях EW, так и LW были в несколько раз ниже (от 2 до 4) нанотвердости клеточных стенок. Вместе с тем измеренная величина $H$ была в несколько раз выше макротвердости $H_{\mathrm{B}}$ по Бринеллю, измеренной нами на тех же образцах, а также справочных данных по твердости и прочности на одноосное растяжение, полученных в макроиспытаниях [66-69]. Эти данные согласуются с результатами [70], где показано, что макротвердость сосны Банкса (Pinus banksiana Lamb.) по Бринеллю $H_{\mathrm{B}}=0.029 \pm 0.005 \mathrm{GPa}$ на порядок величины меньше средней микротвердости клеточных стенок $H=0.297 \pm 0.034 \mathrm{GPa}$. В [60] механические характеристики древесины бука также измеряли на двух масштабных уровнях - в клеточных стенках методом НИ и в годовых кольцах - по Бринеллю вдавливанием 

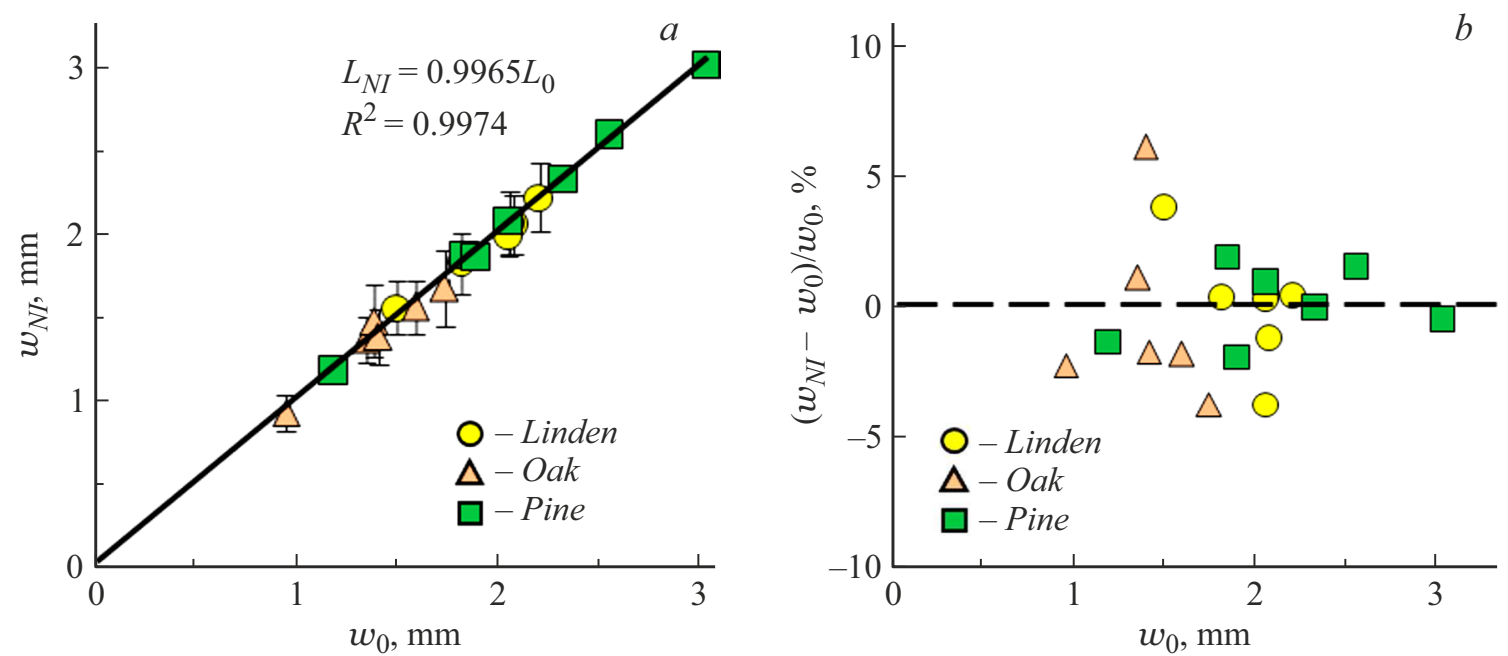

Рис. 8. Результаты измерений ширины годовых колец методом наноиндентирования $w_{N I}$ и оптическим методом $w_{0}(a)$ и расхождения между этими методами $(b)$.

шарика диаметром $2.5 \mathrm{~mm}$ силой $P_{\max }=100 \mathrm{~N}$. Установлено, что $H_{c}=400-500 \mathrm{MPa} \mathrm{почти} \mathrm{на} \mathrm{порядок} \mathrm{величи-}$ ны превышало $H_{\mathrm{B}}=65-70 \mathrm{MPa}$. Очевидно, описанное выше падение механических характеристик с ростом характерных размеров $R^{*}$ объекта испытания можно рассматривать как закономерное следствие проявления РЭ, зарегистрированных в различных видах древесины. Феноменологически они схожи с РЭ, наблюдаемыми в металлах и сплавах, керамиках, композитах и описываемых соотношением Холла-Петча: $\sigma_{y}=\sigma_{0}+A\left(R^{*}\right)^{-0.5}$, где $\sigma_{y}-$ предел текучести, $\sigma_{0}$ и $A-$ константы материала. Аналогичные соотношения действуют и для твердости. Разумеется, причины падения прочности и твердости с ростом $R^{*}$ в разных группах материалов могут быть различными, как и в нано-/микроцеллюлозе, клеточных стенках, слоях ранней и поздней древесины. Их механизмы нуждаются в специальном изучении. Вместе с тем у этих РЭ могут быть найдены и общие причины.

Так, например, ясно, что помимо внутренних механизмов, контролируемых молекулярной и надмолекулярной структурой нанофибрилл и микроволокон целлюлозы, на падение эффективного модуля Юнга и твердости на мезо- и макроуровнях большое влияние оказывает еще и нано-/микропористость древесины, обусловленная наличием пор, капилляров и более крупных трахеид с большим аспектным соотношением. Их присутствие приводит к нескольким существенным отличиям в механическом поведении древесины от сплошных макротел. Во-первых, практически никогда не выполняется правило Тейбора, согласно которому твердость мягких материалов должна превышать предел текучести или прочности примерно в 3 раза. Напротив, в большинстве пород древесины макротвердость, как правило, в несколько раз ниже пределов текучести и прочности на растяжение. По-видимому, во всех подобных явле- ниях причиной является потеря устойчивости ячеистой структуры древесины при индентировании и одноосном сжатии, которая наступает гораздо раньше, чем неупругая деформация и разрушение при растяжении. Ввиду анизотропии механических свойств древесины эти явления сильно зависят от направления приложения нагрузки по отношению к длинной оси клеток и трахеид. Как бы то ни было, из таблицы и литературных данных следует, что в древесине наблюдаются яркие РЭ, вследствие чего прочность/твердость падает от $\sim 10 \mathrm{GPa}$ в нанокристаллической целлюлозе до $\sim 0.1 \mathrm{GPa}$ в макрообъемах древесины. Это означает, что любые целлюлозо-содержащие материалы имеют большой потенциал упрочнения, который можно реализовать с помощью оптимально организованной нано- и микроструктуры и соответствующих технологий.

\section{4. Приложение в дендрохронологии}

Наличие резкого скачка твердости на границах годовых колец позволило определить их ширину $w_{N I}$ по данным сканирующего НИ. Затем их сравнивали с величиной $w_{0}$, которую определяли оптическим методом (по контрасту фотоизображения), аналогичным используемому в широко распространенной линейке оборудования торговой марки LINTAB. Данные сравнения двух этих способов определения ширины годовых колец приведены на рис. 8, из которого следует, что расхождения между ними не превышают в сосне $2-3 \%$, а в дубе и липе - 4-5\%. Среднее отклонение по 6-7 кольцам было около двух раз меньше. Фактически это означает, что метод сканирующего индентирования может использоваться альтернативно по отношению к оптическому или дополнять его сведениями о локальных механических свойствах. 


\section{Заключение}

Сканирующее индентирование с разной максимальной нагрузкой позволяет получать мультимасштабные данные о механических свойствах древесины на различных структурных уровнях - от нано- до макро-. Сопоставление детальной информации о распределении механических характеристик внутри годового кольца, а затем в соседних кольцах роста с макрохарактеристиками позволяет лучше понять природу и механизмы формирования последних. В свою очередь, это может дать новые подходы к оптимизации условий выращивания древесины с заранее заданными механическими свойствами, например, с высокой прочностью и упругостью, необходимыми акустическими характеристиками или низкой скоростью ползучести, а также к физически обоснованным методам упрочнения древесины.

Важно отметить, что предложенная методика сканирования без предварительного отбора точек индентирования и прицеливания в клеточные стенки, выбранная величина $P_{\max }=500 \mathrm{mN}$ и упрощенная процедура подготовки поверхности образца к измерениям, оставляющая часть сошлифованных микроволокон в капиллярах, не только не мешает определению эффективных значений $E$ и $H$, но и имеет ряд преимуществ перед описанными ранее методами измерения $E$ и $H$ в отдельных клеточных стенках при гораздо меньших $P_{\max }$. Во-первых, методика позволяет высокопроизводительно инспектировать большие площади $\left(\sim 10^{4} \mathrm{~mm}^{2}\right.$ и более $)$ вместо единиц $\mathrm{mm}^{2}$ при подготовке их с помощью микротома, во-вторых, соотношение эффективных микротвердостей в LW и EW (с учетом влияния на них пористости и капилляров, а также частичной их заполненности продуктами полировки) намного выше, чем соотношение величин $E$ и $H$ в клеточных стенках LW и EW. Сказанное выше означает, что измерение эффективных значений $H$ и $E$ может быть гораздо более чувствительным методом дендрохронологии и дендроклиматологии, чем использование локальных значений $E$ и $H$ в клеточных стенках и измерение вариаций ширины колец роста.

Метод $1 D$-сканирующего НИ вдоль радиального направления или $2 D$-картирования поперечного среза ствола может быть альтернативным или дополнительным (по отношению к традиционному оптическому) высокоинформативным средством дендрохронологии и дендроклиматологии. В отличие от традиционного он, помимо чисто геометрических характеристик кольцевой структуры роста (ширины годовых колец и слоев ранней и поздней древесины), позволяет проводить с высоким разрешением и внутрикольцевую характеризацию древесины по нескольким параметрам - нано- и микротвердости, модулю Юнга, контактной жесткости и другим механическим характеристикам. Это дает возможность оценивать не только среднегодовые изменения климата, но и внутрисезонные, что представляет интерес для дендрохронологии и дендроклиматологии. Поскольку средний размер клеток в поперечном срезе древесины составляет $30-50 \mu \mathrm{m}$, а средняя ширина годового кольца $-1-3 \mathrm{~mm}$, в нем укладывается 50-100 клеток. В принципе наноиндентирование позволяет измерять механические характеристики каждой клетки. Следовательно, предел временного разрешения дендохронологического применения метода НИ может составлять около 1 недели.

\section{Финансирование работы}

Работа выполнена в Центре коллективного пользования ТГУ им. Г.Р. Державина и поддержана Российским научным фондом, грант 21-14-00233 (исследование распределения локальных механических свойств) и Министерством науки и высшего образования Российской Федерации в рамках проекта по соглашению № 075-15-2021-709, уникальный идентификатор проекта RF-2296.61321Х0037 (подготовка образцов, исследования методом СЭМ).

\section{Конфликт интересов}

Авторы заявляют, что у них нет конфликта интересов.

\section{Список литературы}

[1] Handbook of Nanocellulose and Cellulose Nanocomposites, eds. H. Kargarzadeh, I. Ahmad, S. Thomas, A. Dufresne (Wiley-VCH Verlag GmbH \& Co. KGaA, Weinheim, Germany, 2017)

[2] R.J. Moon, A. Martini, J. Nairn, J. Simonsen, J. Youngblood. Chem. Soc. Rev., 40 (7), 3941 (2011).

DOI: $10.1039 / \mathrm{C} 0 \mathrm{CS} 00108 \mathrm{~B}$

[3] M. Reza, E. Kontturi, A.-S. Jääskeläinen, T. Vuorinen. Bioresources, 10 (3), 6230 (2015). DOI: 10.15376/biores.10.3

[4] A. Balzano, K. Novak, M. Humar, K. Čufar. Les/Wood, 68 (2), 5 (2019). DOI: 10.26614/les-wood.2019.v68n02a01

[5] J. Thomas, D.A. Collings. In book: Wood is Good. Current Trends and Future Prospects in Wood Utilization, eds. K.K. Pandey, V. Ramakantha, S.S. Chauhan, A.N.A. Kumar (Springer Nature Singapore Pte Ltd., 2017), p. 29. DOI: $10.1007 / 978-981-10-3115-1 \_3$

[6] M. Broda, C.-M. Popescu. Spectrochimica Acta. Part A: Molecular and Biomolecular Spectroscopy, 209, 280 (2019). DOI: $10.1016 /$ j.saa.2018.10.057

[7] E.E.N. Alves, D.R.O. Rodriguez, P.A. Rocha, L. Vergütz, L.S. Junior, D. Hesterberg, L.C.R. Pessenda, M. TomazelloFilho, L.M. Costa. Results in Chem., 3, 100121 (2021). DOI: $10.1016 /$ j.rechem.2021.100121

[8] J. Tintner, B. Spangl, F. Reiter, E. Smidt, M. Grabner. Wood Sci. Technol., 54, 313 (2020). DOI: $10.1007 / \mathrm{s} 00226-020-01160-\mathrm{x}$

[9] C.M. Popescu, D. Jones, D. Krzisnik, M. Humar. J. Molecular Structure, 1200, 127133 (2020). DOI: $10.1016 /$ j.molstruc.2019.127133

[10] N. Gierlinger. Appl. Spectr. Rev., 53 (7), 517 (2018). DOI: 10.1080/05704928.2017.1363052 
[11] T. Kanbayashi, Y. Kataoka, A. Ishikawa, M. Matsunaga, M. Kobayashi, M. Kiguchi. J. Photochem. Photobiol., B: Biology, 187, 136 (2018). DOI: $10.1016 /$ j.jphotobiol.2018.08.016

[12] A. Saletnik, B. Saletnik, C. Puchalski. Molecules, 26, 1537 (2021). DOI: 10.3390/molecules 26061537

[13] K. Elsayad, G. Urstoger, C. Czibula, C. Teichert, J. Gumulec, J. Balvan, M. Pohlt, U. Hirn. Cellulose, 27, 4209 (2020). DOI: $10.1007 / \mathrm{s} 10570-020-03075-\mathrm{z}$

[14] X. Kang, A. Kirui, M.C.D. Widanage, F. Mentink-Vigier, D.J. Cosgrove, T. Wang. Nature Commun., 10, 347 (2019). DOI: $10.1038 / \mathrm{s} 41467-018-08252-0$

[15] T. Scharnweber, A. Hevia, A. Buras, E. van der Maaten, M. Wilmking. Sci. Total. Environ, 566-567, 1245 (2016). DOI: $10.1016 /$ j.scitotenv.2016.05.182

[16] E. Toumpanaki, D.U. Shah, S.J. Eichhorn. Adv. Mater., 33 (28), 2001613 (2021). DOI: 10.1002/adma.202001613

[17] L.A. Donaldson. IAWA J., 40 (4), 645 (2019). DOI: $10.1163 / 22941932-40190258$

[18] Nanotribology and Nanomechanics. An Introduction, ed. B. Bhushan. 2nd ed. (Springer, Berlin-Heidelberg-NY., 2008)

[19] Nanomechanical Analysis of High Performance Materials, ed. A. Tiwari. (Springer Science + Business Media, Dordrech-Heidelberg-NY.-London, 2014), 348 p.

[20] Materials Characterization: Modern Methods and Applications, ed. N.M. Ranganathan (CRC Press, Boca Raton, Florida, 2015)

[21] Ю.И. Головин. ФТТ, 63 (1), 3 (2021). DOI: $10.21883 / F T T .2021 .01 .50395 .171$

[22] R. Garcia. Chem. Soc. Rev., 49, 5850 (2020). DOI: $10.1039 / \mathrm{d} 0 \mathrm{cs} 00318 \mathrm{~b}$

[23] B.R. Neugirg, S.R. Koebley, H.C. Schniepp, A. Fery. Nanoscale, 8, 8414 (2016). DOI: 10.1039/c6nr00863a

[24] M. Cascione, V. De Matteis, R. Rinaldi, S. Leporatti. Microsc. Res. Technol., 80, 109 (2017). DOI: 10.1002/jemt.22696

[25] A. Melelli, O. Arnould, J. Beaugrand, A. Bourmaud. Molecules, 25, 632 (2020). DOI: 10.3390/molecules25030632

[26] Ю.И. Головин, В.И. Иволгин, В.В. Коренков, Н.В. Коренкова, Р.И. Рябко. Конденсированные среды и межфазные границы, 3 (2), 122 (2001).

[27] Ю.И. Головин. ФТТ, $50 \quad$ (12), $2113 \quad$ (2008). DOI: $10.1134 / \mathrm{S} 1063783408120019$

[28] Ю.И. Головин. Зав. лаборатория, 75 (1), 45 (2009).

[29] Ю.И. Головин. Наноиндентирование и его возможности (Машиностроение, М., 2009)

[30] A.C. Fischer-Cripps. Nanoindentation (Springer, NY., 2011)

[31] Handbook of Nanoindentation with Biological Applications, ed. M.L. Oyen (Pan Stanford Publishing Pte. Ltd., 2011)

[32] Nanoindentation in Materials Science, ed. J. Nemecek (InTech, London, 2012)

[33] Nanomechanical Analysis of High Performance Materials, ed. A. Tiwari (Springer Science + Business Media. Dordrech-Heidelberg-NY.-London, 2014)

[34] Applied Nanoindentation in Advanced Materials, eds. A. Tiwari, S. Natarajan (John Wiley \& Sons, NY., 2017)

[35] L.J. Gibson. J. Royal Soc., Interface, 9, 2749 (2012). DOI: 10.1098/rsif.2012.0341
[36] M. Ioelovich. In book: Handbook of Nanocellulose and Cellulose Nanocomposites, eds. H. Kargarzadeh, I. Ahmad, S. Thomas, A. Dufresne (Wiley-VCH Verlag GmbH \& Co. Weinheim, Germany, 2017). p. 51. DOI: $10.1002 / 9783527689972 . c h 2$

[37] N. Mittal, F. Ansari, K. Gowda, C. Brouzet, P. Chen, P.T. Larsson, S.V. Roth, F. Lundell, L. Wagberg, N.A. Kotov, L.D. Soderberg. ACS Nano. 12 (7), 6378 (2018). DOI: $10.1021 / \mathrm{acsnano} .8 \mathrm{~b} 01084$

[38] S. Rongpipi, D. Ye, E.D. Gomez, E.W. Gomez. Frontieres in Plant Sci., 9, 1894 (2019). DOI: 10.3389/fpls.2018.01894

[39] N.V. Perepelkin, F.M. Borodich, A.E. Kovalev, S.N. Gorb. Nanomaterials, 10, 15 (2020). DOI: 10.3390/nano10010015

[40] P. Mania, M. Nowicki. Bull. Polish Academy Sci. Tech. Sci., 68 (5), 1237 (2020). DOI: 10.24425bpasts.2020.134645

[41] A.C. Normand, A.M. Charrier, O. Arnould, A.L. Lereu. Scientific Reports, 11, 5739 (2021). DOI: $10.1038 / \mathrm{s} 41598-021-84994-0$

[42] D.M. Meko, J.M. Friedman, R. Touchan, J.R. Edmondson, E.R. Griffin, J.A. Scott. Holocene., 25, 1093 (2015), DOI: $10.1177 / 0959683615580181$

[43] H. Gärtner, P. Cherubini, P. Fonti, G. von Arx, L. Schneider, D. Nievergelt, A. Verstege, A. Bast, F.H. Schweingruber, U. Büntgen. J. Visualized Experiments, 97, e52337 (2015). DOI: $10.3791 / 52337$

[44] X. Zhang, J. Li, X. Liu, Z. Chen. J. For. Res., 31 (2), 1002 (2019). DOI: 10.1007/s11676-019-01002-y

[45] R.J. Kaczka, R. Wilson. Dendrochronologia, 68, 125859 (2021). DOI: 10.1016/j.dendro.2021.125859

[46] A. Vannoppen, S. Maes, V. Kint, T. De Mil, Q. Ponette, J. Van Acker, J.V. den Bulcke, K. Verheyen, B. Muys. Dendrochronologia, 44, 66 (2017).

DOI: 10.1016/j.dendro.2017.03.003

[47] J.V. den Bulcke, M.A. Boone, J. Dhaene, D. Van Loo, L. Van Hoorebeke, M.N. Boone, F. Wyffels, H. Beeckman, J. Van Acker, T. De Mil. Annals of Botany, 124, 837 (2019). DOI: $10.1093 / \mathrm{aob} / \mathrm{mcz} 126$

[48] M. Domínguez-Delmás. Dendrochronologia, 62, 125731 (2020). DOI: $10.1016 / j . d e n d r o .2020 .125731$

[49] J. Martinez-Garcia, I. Stelzner, J. Stelzner, D. Gwerder, P. Schuetz. Dendrochronologia, 69, 125877 (2021). DOI: $10.1016 /$ j.dendro.2021.125877

[50] M. Moria, S. Kuhara, K. Kobayashia, S. Suzuki, M. Yamada, A. Senoo. Dendrochronologia, 57, 125630 (2019). DOI: 10.1016/j.dendro.2019.125630

[51] K. Mayer, M. Grabner, S. Rosner, M. Felhofer, N. Gierlinger. Dendrochronologia, 64, 125781 (2020). DOI: $10.1016 /$ j.dendro.2020.125781

[52] ISO group TC 164/SC 3/WG1 and ASTM E28.06.11. ISO/DIS $14577-1,2,3$.

[53] ГОСТ Р 8.748-2011. Государственная система обеспечения единства измерений. Металлы и сплавы. Измерение твердости и других характеристик материалов при инструментальном индентировании. Ч. 1. Метод испытаний.

[54] W.C. Oliver, G.M. Pharr. J. Mater. Res., 7 (6), 1564 (1992). DOI: $10.1557 / J M R .1992 .1564$

[55] W.C. Oliver, G.M. Pharr. J. Mater. Res, 19 (1), 3 (2004). DOI: $10.1557 / \mathrm{jmr} .2004 .19 .1 .3$

[56] W.C. Oliver, G.M. Pharr. MRS Bull., 35(11), 897 (2010). DOI: $10.1557 / \mathrm{mrs} 2010.717$ 
[57] Ю.И. Головин, А.И. Тюрин, Д.Ю. Головин, А.А. Самодуров, И.А. Васюкова. Изв. вузов. Физика, 63 (11), 187 (2020). DOI: 10.17223/00213411/63/11/187

[58] Ю.И. Головин, А.И. Тюрин, А.А. Гусев, С.М. Матвеев, Д.Ю. Головин. Письма в ЖТФ, 48 (4), 36 (2022). DOI: $10.21883 /$ PJTF.2022.04.52083.19040

[59] I. Carrillo-Varela, P. Valenzuela, W. Gasitua, R.T. Mendoca. BioResources, 14 (3), 6433 (2019). DOI: $10.15376 /$ biores.14.3.6433-6446

[60] S. Stanzl-Tschegg, W. Beikircher, D. Loidl. Holzforschung, 63, 443 (2009). DOI: 10.1515/HF.2009.085

[61] Y. Wu, X. Wu, F. Yang, H. Zhang, X. Feng, J. Zhang. Forests, 11, 1247 (2020). DOI: 10.3390/f11121247

[62] Y.H. Huang, B.H. Fei, Y. Yu, S. Q. Wang, Z.Q. Shi, R.J. Zhao. Bioresources, 7 (3), 3028 (2012).

DOI: 10.15376/biores.7.3.3028-3037

[63] W.T.Y. Tze, S. Wang, T.G. Rials, G.M. Pharr, S.S. Kelley. Composites: Part A. 38, 945 (2007).

DOI: 10.1016/J.COMPOSITESA.2006.06.018

[64] J. Wang, L. Wang, D.J. Gardner, S.M. Shaler, Z. Cai. Cellulose, 28, 4511 (2021). DOI: 10.1007/s10570-021-03771-4

[65] X. Wang, Y. Li, Y. Deng, W. Yu, X. Xie, S. Wang. BioResources, 11 (3), 6026 (2016). DOI: $10.15376 /$ biores.11.3.6026-6039

[66] Электронный ресурс. Режим доступа: lesoteka.com

[67] Электронный ресурс. Режим доступа: extxe.com

[68] А.М. Боровиков, Б.Н. Уголев. Справочник по древесине: Справочник, под ред. Б.Н. Уголева (Лесная промышленность, М., 1989)

[69] Электронный pecypc. Режим доступа: les.novosibdom.ru

[70] M. Vincent, Q. Tong, N. Terziev, G. Daniel, C. Bustos, W.G. Escobar, I. Duchesne. Wood Sci. Technol., 48(1), 7 (2013). DOI: 10.1007/s00226-013-0580-5 